\title{
Familial Mediterranean Fever as an Emerging Clinical Model of Atherogenesis Associated with Low-Grade Inflammation
}

\author{
Şahru Yüksel ${ }^{1, *}$, Lilit Ayvazyan ${ }^{2}$ and Armen Yuri Gasparyan ${ }^{3}$ \\ ${ }^{I}$ Boğaziçi University, Department of Molecular Biology and Genetics, Istanbul, Turkey \\ ${ }^{2}$ Yerevan State Medical University, Yerevan, Armenia \\ ${ }^{3}$ Dudley Group of Hospitals NHS Foundation Trust, West Midlands, UK
}

\begin{abstract}
Numerous inflammatory and innate immune pathways are involved in atherogenesis. Elaboration of clinical models of inflammation-induced atherogenesis may further advance our knowledge of multiple inflammatory pathways implicated in atherogenesis and provide a useful tool for cardiovascular prevention. Familial Mediterranean fever (FMF) is a chronic inflammatory disorder with profiles of inflammatory markers close to that seen in the general population. In a few recent studies, it has been shown that endothelial dysfunction, increased atherosclerotic burden and activation of platelets accompany attack-free periods of FMF. Colchicine is proved to be useful in suppression of inflammation in FMF. Preliminary basic and clinical studies suggest that this relatively safe drug may be useful for cardiovascular protection in patients with FMF and in the general population. Multinational prospective studies are warranted to further elaborate clinical model of inflammation-induced atherosclerosis associated with FMF.
\end{abstract}

Keywords: Familial mediterranean fever, atherosclerosis, endothelial dysfunction, neutrophils, platelets, colchicine.

\section{INTRODUCTION}

Atherosclerosis is the main contributor to the global morbidity and mortality [1]. It starts early in life, progresses slowly and asymptomatically with aging, eventually resulting in atherosclerotic cardiovascular disease, adverse vascular events and death. Staggering amount of evidence derived from experimental and clinical studies suggests that multiple immune and inflammatory agents orchestrate atherosclerotic vasculopathy throughout the whole course of atherogenesis $[2,3]$.

Initial stages of atherosclerotic vasculopathy are characterized by disruption of the integrity of endothelial monolayer, exposure of the constituents of subendothelial space to the blood flow, recruitment of immune and inflammatory cells into the vascular wall, vascular inflammation and decreased production of vasoprotective agents $[4,5]$. An interaction of endothelial cells with T- and B-lymphocytes, neutrophils, platelets and numerous immune and inflammatory agents produced by these cells leads toward atherosclerotic plaque formation, its destabilization and rupture [6-9].

Over the past decade, it has become evident that upregulation of inflammation and autoimmune aggression in certain systemic disorders such as systemic lupus erythematosus (SLE) and rheumatoid arthritis (RA) may substantially accelerate atherogenesis and increase the risk of vascular events [10-12]. Basic and clinical research studies in this

*Address correspondence to this author at the Boğaziçi University, Department of Molecular Biology and Genetics, 34342 Bebek/Istanbul, Turkey; Tel: +90(212) 359-77-84; Fax: +90 (212) 287-2468;

E-mail: sahru.yuksel@boun.edu.tr field have led to the emergence of a new biomedical discipline, vascular rheumatology [13], which aims to clarify pathophysiology of rheumatic diseases and co-morbidities and to propose recommendations for primary and secondary prevention of vascular events in the general population. Clinical models of inflammation-induced atherosclerosis elaborated over the past decade are mainly based on the cardiovascular phenomenon described within the frames of high-grade inflammatory conditions. Much less attention has been paid to atherogenesis in low-grade inflammatory conditions, such as psoriatic arthritis [14, 15], ankylosing spondylitis [16] and familial Mediterranean fever (FMF) [17, 18] which manifest with inflammatory profiles close to that seen in the general population. Better understanding of diverse inflammatory pathways associated with atherogenesis may provide useful tools for cardiovascular prevention with drugs proved their efficiency in these disorders (for example, colchicine in FMF).

The aim of the current mini-review is to discuss latest data supporting the concept of FMF as a clinical model of atherogenesis associated with low-grade inflammation.

\section{FMF AS A LOW-GRADE INFLAMMATORY DISORDER}

FMF has been classified as a systemic autoinflammatory disorder characterized by seemingly unprovoked activation of diverse inflammatory pathways $[19,20]$. It is an ancient disease with wide-spread distribution in the Eastern Mediterranean region and sporadic occurrence throughout the world. The etiopathophysiology of FMF is not fully understood. 
However, it is largely recognized as an autosomal recessive trait associated with missense mutations in the MEditerranean FeVer (MEFV) gene located on the short arm of chromosome 16 [21]. The gene is predominantly expressed in neutrophils [22]. The mutant pyrin protein encoded by the MEFV gene contains 781 amino acids and 4 domains (pyrin N-terminal, B-BOX type zinc finger, Coiled Coil and B30.2 C-terminal). The B30.2 domain encoded by the last, $10^{\text {th }}$ exon of the MEFV gene which is the location of all severe mutations (M694V, M694I, M680I) [21]. These mutations are responsible for dysregulation of apoptosis and inflammation due to the reduced ability of the mutated pyrin protein to modulate activity of inflammasome and interleukin-1beta (IL-1beta) [19]. Importantly, the same mutations were found responsible for subclinical inflammation in apparently healthy subjects $[23,24]$ and were associated with myocardial infarction (MI) in the general population [25], severe course of inflammation with arthritis in inflammatory bowel disease [26], vascular involvement in Behçet's disease (BD) [27].

The hallmark of FMF is a self-limiting febrile attack of polyserositis followed by attack-free period. In a large proportion of patients symptom-free intervals of the disease are characterized by subclinical inflammation with overproduction of C-reactive protein (CRP), serum amyloid A (SAA) and other acute-phase reactants [28,29]. During attack-free periods, patients with FMF may still experience arthritis, myalgia, autonomic dysregulation with altered cardiovascular reactivity [30] and other cardiovascular symptoms related to persistent subclinical inflammation [18]. Importantly, recent studies with cardiovascular imaging techniques identified signs of diastolic dysfunction and microvascular coronary pathology which were correlated with elevated levels of CRP during attack-free period [31, 32]. Clinical significance of coronary pathology in FMF was also highlighted in a few previous reports of coronary vasculitis, transient left bundle branch block and MI associated with inflammation in FMF [33-35].

Persistent inflammation in FMF may cause endothelial dysfunction, atherothrombosis and systemic amyloidosis, all of which share some genetic, immunological and morphological features [36]. Systemic amyloidosis is the most dreadful manifestation of the disease which define its outcome [37, 38]. Rarely, amyloidosis in FMF affects the myocardium and coronary vessels [39-41].

\section{ENDOTHELIAL DYSFUNCTION IN FMF}

Endothelial cells play a crucial role in the migration of activated neutrophils into the subendothelial space and in the initiation of the vessel wall inflammation [42]. Endothelial adhesion molecules, such as intercellular adhesion molecule-1 (ICAM-1) and vascular cell adhesion molecule-1 (VCAM-1), facilitate cellular interactions between neutrophils, T- and B-lymphocytes, monocytes/macrophages, endothelial cells, whereas neutrophils, as an abundant source of oxygen reactive species and proteolytic enzymes, act against endothelial cell junctions, thus opening route toward vascular smooth muscle cell [43]. This basic mechanism of endothelial dysfunction initiated by neutrophils underlies diverse disorders associated with inflammation [44, 45] and may play even more active role in FMF.

Though vasculopathic cellular and molecular agents are not fully explored within the frames of FMF, neutrophils are believed to be the main inflammatory cells implicated in endothelial dysfunction, oxidative stress and overproduction of adhesion molecules in this disorder [46]. Neutrophils of patients with FMF may remain hyperactive during attackfree period due to the sustained overproduction of interleukins-17 (IL-17) and -18 (IL-18) [47]. Of note, IL-18 is one of the main pro-inflammatory cytokines, exerting its proatherogenic effects via inflammasome activation and release of adhesion molecules [48], secretion of interferon-gamma [49] and upregulation of other pro-inflammatory cytokines (e.g., interleukin-8 [IL-8]) [50].

It has been shown that attack-free period in FMF is characterized by ongoing endothelial damage with elevation of circulating markers of endothelial dysfunction such as thrombomodulin [51], adrenomedullin and nitrite [52]. Elevated CRP [53] and vascular endothelial growth factor $[54,55]$ can be considered as direct contributors to the vascular damage and endothelial dysfunction in FMF.

\section{PROTHROMBOTIC STATE IN FMF}

Over the past few years, several reports have been published, linking subclinical inflammation with markers of hypercoagulation and thrombosis in FMF [56-60]. As a result, it has become possible to formulate hypothesis which considers FMF as a prothrombotic disorder [57]. Interestingly, implications of the MEFV gene in thrombosis have not been investigated in FMF, but its common mutations have been associated with the susceptibility to venous thrombosis in BD [61].

Hypercoagulation in attack-free period in FMF was characterized by shortened prothrombin time and thrombin time, decreased protein $\mathrm{C}$ activity and elevation of prothrombin fragment F1+2 [56]. Besides, in one study, platelet activation was documented by an increase of the size of circulating platelets during the same period in FMF [62]. However, in another similar study, there was no difference in platelet function among patients with FMF and healthy controls which was interpreted as a positive (anti-platelet) effect of colchicine therapy [63].

It should be emphasized that platelet activation is an essential link between inflammatory, thrombotic and atherogenic pathways [64]. Activated platelets interact with neutrophils and endothelial cells and through the release of P-selectin and other pro-inflammatory agents facilitate participation of immune cells in vascular inflammation and atherogenesis [65].

In this regard, further studies are warranted to investigate interaction of platelets with markers of inflammation derived from other cells (e.g., IL-8, neutrophilic enzymes, CRP) and to determine vascular predictive value of activated platelets in FMF. 


\section{ATHEROSCLEROTIC BURDEN IN FMF}

Surrogate markers of atherosclerosis, such as the carotid artery intima-media thickness (IMT) has emerged as an useful tool for assessment of the burden of atherosclerosis and efficiency of cardiovascular therapies [66]. In most studies, the observed association of circulating inflammatory markers with an increased carotid artery IMT in chronic inflammatory disorders led to a conclusion that these disorders are associated with accelerated atherosclerosis and heightened risk of atherothrombotic events [67].

Atherosclerotic burden measured by the carotid artery IMT was also assessed in patients with FMF [17, 68-71]. Intima-media thickening was associated with elevation of SAA and fibrinogen during attack-free period [17]. None of the studies investigating carotid atherosclerosis in FMF found an increase of the prevalence of atherosclerotic plaques which was seen in high-grade inflammatory disorders (e.g., SLE, RA). The latter can be interpreted as a result of less aggressive course of atherosclerosis in FMF [71]. It is, however, possible to speculate that colchicine therapy was responsible for less aggressive course of atherogenesis in the most studies in FMF. Prospective studies with the patients examined for atherosclerotic burden at baseline (when the diagnosis is made and colchicine administered) and at several time-points of the long-term follow-up, most probably, will ascertain whether colchicine affects the course of atherogenesis in FMF.

\section{COLCHICINE THERAPY AND ATHEROGENESIS}

Colchicine is an alkaloid derived from the plant Colchicum autumnale. Extract of the plant has been successfully used for the treatment of gouty arthritis for centuries [72]. Also, colchicine has been demonstrated effectiveness in various inflammatory and (auto)immune disorders (e.g., liver cirrhosis, necrotizing vasculitis, BD, psoriasis, scleroderma, sarcoidosis, thrombocytopenic purpura, pericarditis, skin diseases with neutrophils infiltration) [72, 73]. However, the first report on successful treatment of attacks of FMF with colchicine published in 1972 [74] and large clinical trials $[75,76]$ distinguished colchicine as a drug of choice for prevention of attacks and amyloidosis in FMF. As a result, nowadays, regular colchicine intake at a dose of 1-2 mg/day is considered as a relatively safe and effective therapeutic option for the suppression of inflammation and prevention of inflammatory co-morbidities in FMF [77].

The main mechanism of action of colchicine, favoring its use in FMF, is dependent on selective accumulation in neutrophils, disruption of polymerization of microtubules, and suppression of neutrophils chemotaxis [78]. Colchicine alters expression of the MEFV [79] and other genes regulating inflammatory pathways [80] exerts anti-cytokinergic and fibrolytic effects $[81,82]$ further expanding its use in inflammatory disorders (most notably in recurrent pericarditis [83]).

Preliminary data suggest that anti-inflammatory profile of colchicine may have cardiovascular implications in FMF. In a 6-month colchicine trial, patients with FMF at preamy- loidal and early amyloidal stages demonstrated significant improvement of diastolic function [84]. In another retrospective study with a large cohort of FMF patients $(n=290)$ regularly treated with colchicine the prevalence of ischemic heart disease (IHD) and established cardiovascular risk factors were comparable to that of healthy controls [85].

Promising results of the studies on anti-inflammatory and cardioprotective effects of colchicine in FMF made it possible to investigate benefits of colchicine in patients with cardiovascular disease with elevated levels of inflammatory markers. In particular, in a one-month study with 44 patients with stable IHD and elevated CRP $(>2.0 \mathrm{mg} / \mathrm{L})$, colchicine $(1 \mathrm{mg} /$ day) significantly lowered CRP without side effects [86]. Unfortunately, owing to the safety concerns, there are no long-term studies which could clarify whether the observed effect on CRP has implications in terms of reducing vascular events.

Established short-term anti-inflammatory effects and safety profile of colchicine may however have implications for prevention of restenosis in patients undergoing percutaneous transluminal angioplasty. Although clinical evidence to support this hypothesis is non-existent (perhaps due to the safety concerns), one recent experimental study on angioplasty of iliofemoral arteries in dogs demonstrated safety and dose-dependent potential of colchicine in preventing intimal hyperplasia within 2 weeks of the drug therapy [87]. Importantly, further studies in different animal models of angioplasty at coronary and other vascular sites with different regimes of colchicine therapy (oral intake, local application, low, moderate, high doses) are warranted before clinical studies.

\section{CONCLUSIONS}

Preliminary studies suggest that attack-free periods of FMF are characterized by subclinical inflammation and associated endothelial dysfunction, increased atherosclerotic burden and platelets activation. Colchicine demonstrated relatively safe anti-inflammatory potential which seems potentially useful for amelioration of endothelial function, suppression of prothrombotic pathways and decrease of atherosclerotic burden (Fig. 1). The effects of colchicine on cardiovascular morbidity and mortality have not been studied prospectively. Nevertheless, clinical experience on regular colchicine therapy accumulated over the past decades suggests that in populations of patients exposed to colchicine from early stages of the disease (e.g., the patients from Israel) the prevalence of IHD is not higher than that in the general population [85]. Moreover, in most previous retrospective studies, those on regular colchicine therapy were free of established cardiovascular risk factors, such as dyslipidemia and hypertension. Given the differences in clinical manifestations, cardiovascular risk profiles and responsiveness to colchicine in populations of FMF patients from different countries, multinational prospective studies with emphasis on established and novel risk factors and vascular events in FMF are recommended.

New opportunities for targeted use of cardiovascular and disease-modifying drugs in FMF and other low-grade 


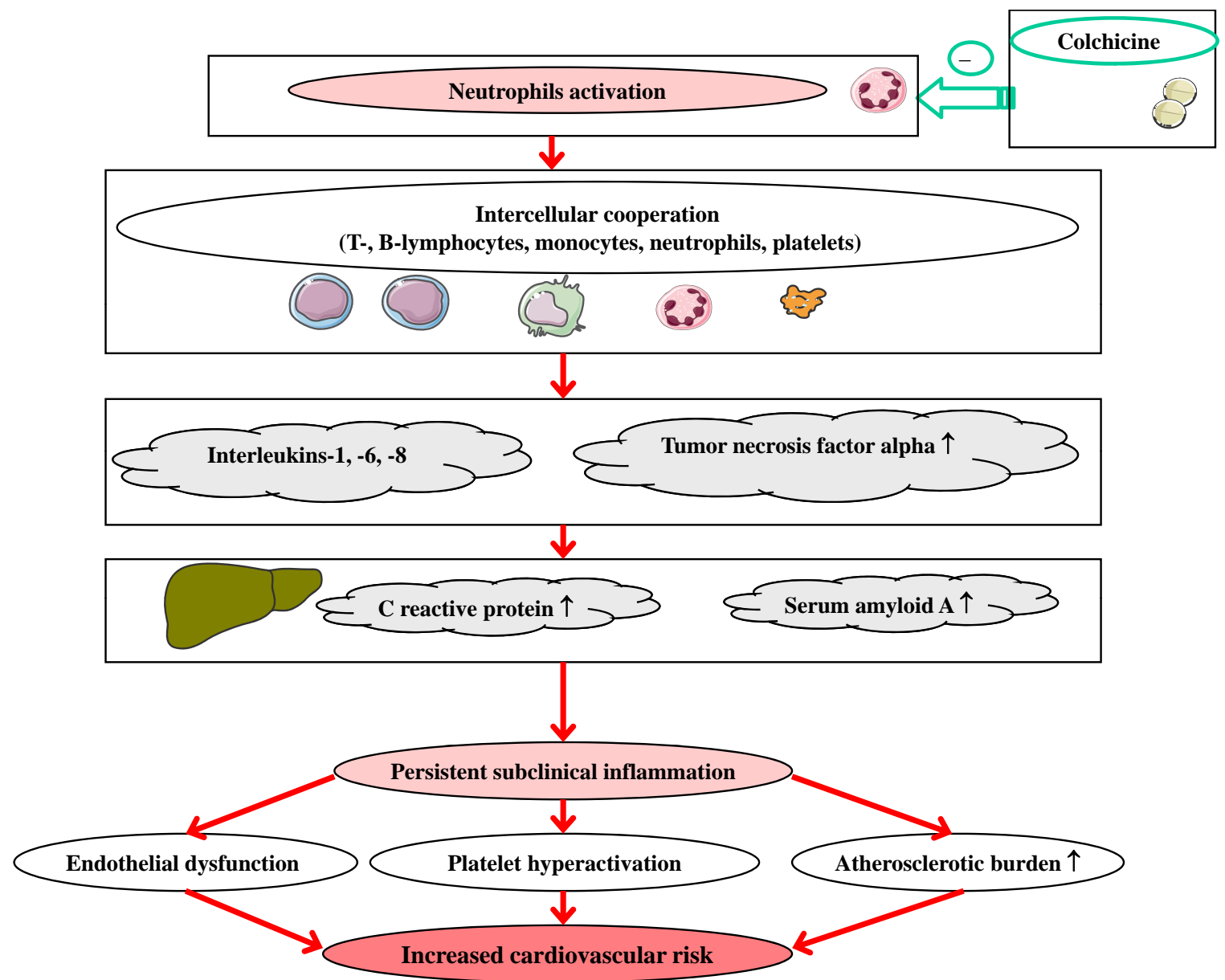

Fig. (1). Potential implications of colchicine therapy in atherogensis in FMF.

inflammatory disorders may emerge with future prospective studies specifically looking at cardiovascular risk profiles in association with several inflammatory (IL-1beta, IL-6, IL-8, TNF-alpha, IL-18) and genetic markers (the MEFV gene mutations).

\section{REFERENCES}

[1] Lopez AD, Mathers CD, Ezzati M, Jamison DT, Murray CJ. Global and regional burden of disease and risk factors, 2001: systematic analysis of population health data. Lancet 2006; 367: 1747-57.

[2] Libby P. Inflammation in atherosclerosis. Nature 2002; 420: 86874.

[3] Ikeda U. Inflammation and coronary artery disease. Curr Vasc Pharmacol 2003; 1: 65-70.

[4] Ferri C, Croce G, Cofini V, et al. C-reactive protein: interaction with the vascular endothelium and possible role in human atherosclerosis. Curr Pharm Des 2007; 13: 1631-45.

[5] Nakou ES, Liberopoulos EN, Milionis HJ, Elisaf MS. The role of C-reactive protein in atherosclerotic cardiovascular disease: an overview. Curr Vasc Pharmacol 2008; 6: 258-70.

[6] Ley K, Laudanna C, Cybulsky MI, Nourshargh S. Getting to the site of inflammation: the leukocyte adhesion cascade updated. Nat Rev Immunol 2007; 7: 678-89.

[7] Schäfer A, Bauersachs J. Endothelial dysfunction, impaired endogenous platelet inhibition and platelet activation in diabetes and atherosclerosis. Curr Vasc Pharmacol 2008; 6: 52-60.

[8] McNicol A, Israels SJ. Beyond hemostasis: the role of platelets in inflammation, malignancy and infection. Cardiovasc Hematol Disord Drug Targets 2008; 8: 99-117.
[9] Galkina E, Ley K. Immune and inflammatory mechanisms of atherosclerosis (*). Annu Rev Immunol 2009; 27: 165-97.

[10] Shoenfeld Y, Gerli R, Doria A, et al. Accelerated atherosclerosis in autoimmune rheumatic diseases. Circulation 2005; 112: 3337 47.

[11] Montecucco F, Mach F. Common inflammatory mediators orchestrate pathophysiological processes in rheumatoid arthritis and atherosclerosis. Rheumatology (Oxford) 2009; 48: 11-22.

[12] Kaplan MJ. Management of cardiovascular disease risk in chronic inflammatory disorders. Nat Rev Rheumatol 2009; 5: 208-17.

[13] Szekanecz Z, Koch AE. Vascular involvement in rheumatic diseases: 'vascular rheumatology'. Arthritis Res Ther 2008; 10: 224.

[14] Alexandroff AB, Pauriah M, Camp RD, Lang CC, Struthers AD, Armstrong DJ. More than skin deep: atherosclerosis as a systemic manifestation of psoriasis. Br J Dermatol 2009; 161: 1-7.

[15] Gisondi P, Girolomoni G. Psoriasis and atherothrombotic diseases: disease-specific and non-disease-specific risk factors. Semin Thromb Hemost 2009; 35: 313-24.

[16] Mathieu S, Joly H, Baron G, et al. Trend towards increased arterial stiffness or intima-media thickness in ankylosing spondylitis patients without clinically evident cardiovascular disease. Rheumatology (Oxford) 2008; 47: 1203-7.

[17] Bilginer Y, Ozaltin F, Basaran C, et al. Evaluation of intima media thickness of the common and internal carotid arteries with inflammatory markers in familial Mediterranean fever as possible predictors for atherosclerosis. Rheumatol Int 2008; 28: 1211-6.

[18] Gasparyan AY, Ugurlucan M. The emerging issue of cardiovascular involvement in familial Mediterranean fever. Arch Med Sci 2008; 4: 465-7.

[19] Chae JJ, Aksentijevich I, Kastner DL. Advances in the understanding of familial Mediterranean fever and possibilities for targeted therapy. Br J Haematol 2009; 146: 467-78. 
[20] Gattorno M, La Regina M, Martini A, Manna R. An update on autoinflammatory diseases. New concepts for new and old diseases. Clin Exp Rheumatol 2009; 27: 354-65.

[21] Fonnesu C, Cerquaglia C, Giovinale M, et al. Familial Mediterranean Fever: a review for clinical management. Joint Bone Spine 2009; 76: 227-33.

[22] Centola M, Wood G, Frucht DM, et al. The gene for familial Mediterranean fever, MEFV, is expressed in early leukocyte development and is regulated in response to inflammatory mediators. Blood 2000; 95: 3223-31.

[23] Ozen S, Bakkaloglu A, Yilmaz E, et al. Mutations in the gene for familial Mediterranean fever: do they predispose to inflammation? J Rheumatol 2003; 30: 2014-8.

[24] Kalyoncu M, Acar BC, Cakar N, et al. Are carriers for MEFV mutations "healthy"? Clin Exp Rheumatol 2006; 24 (5 Suppl 42): S120-2.

[25] Candore G, Balistreri CR, Grimaldi MP, et al. Opposite role of proinflammatory alleles in acute myocardial infarction and longevity: results of studies performed in a Sicilian population. Ann NY Acad Sci 2006; 1067: 270-5.

[26] Giaglis S, Mimidis K, Papadopoulos V, et al. Increased frequency of mutations in the gene responsible for familial Mediterranean fever (MEFV) in a cohort of patients with ulcerative colitis: evidence for a potential disease-modifying effect? Dig Dis Sci 2006; 51: 687-92.

[27] Atagunduz P, Ergun T, Direskeneli H. MEFV mutations are increased in Behçet's disease (BD) and are associated with vascular involvement. Clin Exp Rheumatol 2003; 21 (4 Suppl 30): S35-7.

[28] Lachmann HJ, Sengül B, Yavuzşen TU, et al. Clinical and subclinical inflammation in patients with familial Mediterranean fever and in heterozygous carriers of MEFV mutations. Rheumatology (Oxford) 2006; 45: 746-50.

[29] Korkmaz C, Ozdogan H, Kasapçopur O, Yazici H. Acute phase response in familial Mediterranean fever. Ann Rheum Dis 2002; 61: 79-81.

[30] Rozenbaum M, Naschitz JE, Yudashkin M, et al. Cardiovascular reactivity score for the assessment of dysautonomia in familial Mediterranean fever. Rheumatol Int 2004; 24: 147-52.

[31] Caliskan M, Gullu H, Yilmaz S, et al. Impaired coronary microvascular function in familial Mediterranean fever. Atherosclerosis 2007; 195: e161-7.

[32] Tavil Y, Ureten K, Oztürk MA, et al. The detailed assessment of left and right ventricular functions by tissue Doppler imaging in patients with familial Mediterranean fever. Clin Rheumatol 2008; 27 : 189-94.

[33] Hamuryudan V, Ozdoğan H, Yazici H. Other forms of vasculitis and pseudovasculitis. Baillieres Clin Rheumatol 1997; 11: 335-55.

[34] Serrano R, Martínez MA, Andrés A, Morales JM, Samartin R. Familial mediterranean fever and acute myocardial infarction secondary to coronary vasculitis. Histopathology 1998; 33: 163-7.

[35] Cocco G. Vasculitis, left bundle branch block, and Raynaud's phenomenon as a manisfestation of familial Mediterranean fever. Arch Med Sci 2008; 4: 460-4.

[36] Thurmon TF. Genetics, aging, and the heart. J La State Med Soc 1998; 150: 356-66.

[37] Manna R, Cerquaglia C, Curigliano V, et al. Clinical features of familial Mediterranean fever: an Italian overview. Eur Rev Med Pharmacol Sci 2009; 13(Suppl 1): 51-3.

[38] Lachmann HJ, Hawkins PN. Developments in the scientific and clinical understanding of autoinflammatory disorders. Arthritis Res Ther 2009; 11: 212.

[39] Yildiz A, Akkaya V, Kiliçaslan I, et al. Cardiac and intestinal amyloidosis in a renal transplant recipient with familial Mediterranean fever. J Nephrol 2001; 14: 125-7.

[40] Keven K, Oztas E, Aksoy H, Duman N, Erbay B, Ertürk S. Polyglandular endocrine failure in a patient with amyloidosis secondary to familial Mediterranean fever. Am J Kidney Dis 2001; 38: E39.

[41] Gasparyan AY, Petrosyan AH. Cardiac involvement in familial Mediterranean fever. Cardiovas Ther Prevent (Moscow) 2007; 6 (6): 117-24.

[42] Muller WA. Mechanisms of transendothelial migration of leukocytes. Circ Res 2009; 105: 223-30.

[43] Wittchen ES. Endothelial signaling in paracellular and transcellular leukocyte transmigration. Front Biosci 2009; 14: 2522-45.

[44] Ungvári Z, Gupte SA, Recchia FA, Bátkai S, Pacher P. Role of oxidative-nitrosative stress and downstream pathways in various forms of cardiomyopathy and heart failure. Curr Vasc Pharmacol 2005; 3: 221-9.

[45] Zalba G, Fortuño A, San José G, Moreno MU, Beloqui O, Díez J. Oxidative stress, endothelial dysfunction and cerebrovascular disease. Cerebrovasc Dis 2007; 24(Suppl 1): 24-9.

[46] Direskeneli H, Ozdogan H, Korkmaz C, Akoglu T, Yazici H. Serum soluble intercellular adhesion molecule 1 and interleukin 8 levels in familial Mediterranean fever. J Rheumatol 1999; 26: 1983-6.

[47] Haznedaroglu S, Oztürk MA, Sancak B, et al. Serum interleukin 17 and interleukin 18 levels in familial Mediterranean fever. Clin Exp Rheumatol 2005; 23 (4 Suppl 38): S77-80.

[48] Gerdes N, Sukhova GK, Libby P, Reynolds RS, Young JL, Schönbeck U. Expression of interleukin (IL)-18 and functional IL-18 receptor on human vascular endothelial cells, smooth muscle cells, and macrophages: implications for atherogenesis. J Exp Med 2002; 195: 245-57.

[49] Whitman SC, Ravisankar P, Daugherty A. Interleukin-18 enhances atherosclerosis in apolipoprotein $\mathrm{E}(-/-)$ mice through release of interferon-gamma. Circ Res 2002; 90: E34-8.

[50] Kleemann R, Zadelaar S, Kooistra T. Cytokines and atherosclerosis: a comprehensive review of studies in mice. Cardiovasc Res 2008; 79: 360-76.

[51] Ozbalkan Z, Ozturk MA, Onat AM, et al. Circulating thrombomodulin levels in familial Mediterranean fever. Clin Exp Rheumatol 2006; 24 (5 Suppl 42): S95-8.

[52] Balat A, Işlek I, Cekmen M, et al. Adrenomedullin and total nitrite levels in children with familial Mediterranean fever. J Paediatr Child Health 2006; 42: 240-3.

[53] Terekeci HM, Oktenli C, Ozgurtas T, et al. Increased asymmetric dimethylarginine levels in young men with familial Mediterranean fever (FMF): is it early evidence of interaction between inflammation and endothelial dysfunction in FMF? J Rheumatol 2008; 35 : 2024-9.

[54] Gunesacar R, Erken E, Ozer HT, Bozkurt B, Dinkci S, Deveci D. Analysis of vascular endothelial growth factor gene $936 \mathrm{C} / \mathrm{T}$ polymorphism in patients with familial Mediterranean fever. Int $\mathbf{J}$ Immunogenet 2008; 35: 33-6.

[55] Başar O, Oztürk MA, Köklü S, et al. Plasma levels of soluble vascular endothelial growth factor receptor-1 (sVEGFR-1) in familial Mediterranean fever. Joint Bone Spine 2007; 74: 52-5.

[56] Aksu G, Ozturk C, Kavakli K, Genel F, Kutukculer N. Hypercoagulability: interaction between inflammation and coagulation in familial Mediterranean fever. Clin Rheumatol 2007; 26: 36670.

[57] Demirel A, Celkan T, Kasapcopur O, et al. Is Familial Mediterranean Fever a thrombotic disease or not? Eur J Pediatr 2008; 167 : 279-85.

[58] Aoun EG, Musallam KM, Uthman I, Beydoun A, El-Hajj T, Taher AT. Childhood stroke in a child with familial Mediterranean fever carrying several prothrombotic risk factors. Lupus 2009; 18 : 845-7.

[59] Sari S, Egritas O, Bukulmez A, Dalgic B, Soylemezoglu O. Is familial mediterranean fever a possible cofactor for budd-chiari syndrome? J Pediatr Gastroenterol Nutr 2009; 49(4): 481-4.

[60] Ozel Demiralp DF, Ekim M, Akar N. The effect of plasminogen activator inhibitor-1 -675 4G/5G polymorphism on Familial Mediterranean Fever (FMF) Disease. Clin Appl Thromb Hemost 2009; 15(4): 443-7.

[61] Rabinovich E, Shinar Y, Leiba M, Ehrenfeld M, Langevitz P, Livneh A. Common FMF alleles may predispose to development of Behcet's disease with increased risk for venous thrombosis. Scand J Rheumatol 2007; 36: 48-52.

[62] Coban E, Adanir H. Platelet activation in patients with Familial Mediterranean Fever. Platelets 2008; 19: 405-8.

[63] Makay B, Türkyilmaz Z, Unsal E. Mean platelet volume in children with familial Mediterranean fever. Clin Rheumatol 2009; 28: 975-8.

[64] Wagner DD, Burger PC. Platelets in inflammation and thrombosis. Arterioscler Thromb Vasc Biol 2003; 23: 2131-7.

[65] Smid J, Braun-Dullaeus R, Gawaz M, Langer HF. Platelet interactions as therapeutic targets for prevention of atherothrombosis. Future Cardiol 2009; 5: 285-96.

[66] Bots ML. Carotid intima-media thickness as a surrogate marker for cardiovascular disease in intervention studies. Curr Med Res Opin 2006; 22: 2181-90. 
[67] Gasparyan AY. The use of carotid artery ultrasonography in different clinical conditions. Open Cardiovasc Med J 2009; 3: 78-80.

[68] Sari I, Karaoglu O, Can G, et al. Early ultrasonographic markers of atherosclerosis in patients with familial Mediterranean fever. Clin Rheumatol 2007; 26: 1467-73.

[69] Akdogan A, Calguneri M, Yavuz B, et al. Are familial Mediterranean fever (FMF) patients at increased risk for atherosclerosis? Impaired endothelial function and increased intima media thickness are found in FMF. J Am Coll Cardiol 2006; 48: 2351-3.

[70] Peru H, Altun B, Doğan M, Kara F, Elmaci AM, Oran B. The evaluation of carotid intima-media thickness in children with familial Mediterranean fever. Clin Rheumatol 2008; 27: 689-94.

[71] Ugurlu S, Seyahi E, Cetinkaya F, Ozbakir F, Balci H, Ozdogan H. Intima-media thickening in patients with familial Mediterranean fever. Rheumatology (Oxford) 2009; 48: 911-5.

[72] Ben-Chetrit E, Levy M. Colchicine: 1998 update. Semin Arthritis Rheum 1998; 28: 48-59.

[73] Niel E, Scherrmann JM. Colchicine today. Joint Bone Spine 2006; 73: 672-8.

[74] Goldfinger SE. Colchicine for familial Mediterranean fever. N Engl J Med 1972; 287: 1302

[75] Dinarello CA, Wolff SM, Goldfinger SE, Dale DC, Alling DW. Colchicine therapy for familial mediterranean fever. A doubleblind trial. N Engl J Med 1974; 291: 934-7.

[76] Goldfinger SE. Familial Mediterranean fever--a progress report. West J Med 1977; 127: 40-1.

[77] Cerquaglia C, Diaco M, Nucera G, La Regina M, Montalto M, Manna R. Pharmacological and clinical basis of treatment of Familial Mediterranean Fever (FMF) with colchicine or analogues: an update. Curr Drug Targets Inflamm Allergy 2005; 4: 117-24.

[78] Ben-Chetrit E, Levy M. Does the lack of the P-glycoprotein efflux pump in neutrophils explain the efficacy of colchicine in familial Mediterranean fever and other inflammatory diseases? Med Hypotheses 1998; 51: 377-80.
[79] Abedat S, Urieli-Shoval S, Shapira E, Calko S, Ben-Chetrit E, Matzner Y. Effect of colchicine and cytokines on MEFV expression and $\mathrm{C} 5 \mathrm{a}$ inhibitor activity in human primary fibroblast cultures. Isr Med Assoc J 2002; 4: 7-12.

[80] Ben-Chetrit E, Bergmann S, Sood R. Mechanism of the antiinflammatory effect of colchicine in rheumatic diseases: a possible new outlook through microarray analysis. Rheumatology (Oxford) 2006; 45: 274-82.

[81] Entzian P, Schlaak M, Seitzer U, Bufe A, Acil Y, Zabel P. Antiinflammatory and antifibrotic properties of colchicine: implications for idiopathic pulmonary fibrosis. Lung 1997; 175: 41-51.

[82] De Socio G, Cerquaglia C, Curigliano V, et al. Association between familial mediterranean fever and retroperitoneal fibrosis: retroperitoneal fibrosis regression after colchicine therapy. Int J Immunopathol Pharmacol 2009; 22: 521-4.

[83] Imazio M, Bobbio M, Cecchi $\mathrm{E}$, et al. Colchicine as first-choice therapy for recurrent pericarditis: results of the CORE (COlchicine for REcurrent pericarditis) trial. Arch Intern Med 2005; 165: 198791.

[84] Gasparyan AY. Effect of colchicine on ventricular diastolic reserve and pulmonary blood flow state in familial Mediterranean fever. J Arrhythmology (Saint-Petersburg) 2001; (24): 27-30.

[85] Langevitz P, Livneh A, Neumann L, et al. Prevalence of ischemic heart disease in patients with familial Mediterranean fever. Isr Med Assoc J 2001; 3: 9-12.

[86] Nidorf M, Thompson PL. Effect of colchicine (0.5 mg twice daily) on high-sensitivity C-reactive protein independent of aspirin and atorvastatin in patients with stable coronary artery disease. Am J Cardiol 2007; 99: 805-7.

[87] Atta HM, El-Rehany MA, Abdel Raheim SR, Fouad R, Galal AM. Colchicine inhibits intimal hyperplasia and leukocyte VEGF expression in dogs. J Surg Res 2008; 146: 184-9.

This is an open access article licensed under the terms of the Creative Commons Attribution Non-Commercial License (http://creativecommons.org/licenses/ by-nc/3.0/) which permits unrestricted, non-commercial use, distribution and reproduction in any medium, provided the work is properly cited. 